\title{
Wnt signaling in development and disease
}

\author{
Jennifer L. Freese*, Darya Pino*, and Samuel J. Pleasure \\ Department of Neurology, Programs in Neuroscience, Developmental Biology and Biomedical \\ Sciences, University of California, San Francisco, CA
}

\begin{abstract}
The Wnt signaling pathway is one of the central morphogenic signaling pathways regulating early vertebrate development. In recent years it's become clear that the Wnt pathway also regulates many aspects of nervous system development from the patterning stage through the regulation of neural plasticity. In this review, we first present an overview of the components of the Wnt-signaling pathway and then go on to discuss the literature describing the multitude of roles of Wnts in nervous system. In the latter portion of the review we turn to the ways that defects in Wnt signaling lead to neurologic disease.
\end{abstract}

\section{Wnt Pathways}

Wnts are secreted glycoproteins that play essential roles in embryogenesis and cortical development. As ligands, Wnts interact with 7-transmembrane, G-protein-coupled receptors called Frizzleds (Fz) to initiate several different signaling pathways (Figure 1). The best understood Wnt signaling mechanism - the "canonical" pathway-involves the stabilization and translocation of $\beta$-catenin to the nucleus. There it acts as a component of a transcriptional signaling complex with members of the Tcf/Lef family of transcription factors to activate target genes (Huang and He, 2008). Absent Wnt signaling, $\beta$-catenin is phosphorylated then targeted for degradation in proteosomes via ubiquitization.

Rather than stabilizing $\beta$-catenin, the "Wnt-calcium" pathway utilizes G-protein second messenger systems to mobilize intracellular calcium stores and activate atypical PKC and other calcium responsive pathways (Kuhl et al., 2001; Kuhl et al., 2000a; Kuhl et al., 2000b; Slusarski et al., 1997). A third Wnt pathway couples short-term cytoskeletal reorganization, convergent extension and control of planar polarity through activation of Rho-type GTPases and Jun Nterminal (JNK) serine/threonine kinase (Kohn and Moon, 2005). This is called the "Planar Cell Polarity" pathway, or "PCP." It is unclear whether the calcium and PCP pathways are truly separable or part of an interconnected signaling web along with the several other reported signaling pathways. Many of the non-canonical effects of Wnt signaling depend on signaling pathways that directly or indirectly regulate cytoskeletal dynamics at or near the cell membrane (Semenov et al., 2007).

\footnotetext{
Address Correspondence to: Samuel J. Pleasure, MD/PhD sam.pleasure@ucsf.edu.

These authors contributed equally and are listed alphabetically.

Publisher's Disclaimer: This is a PDF file of an unedited manuscript that has been accepted for publication. As a service to our customers we are providing this early version of the manuscript. The manuscript will undergo copyediting, typesetting, and review of the resulting proof before it is published in its final citable form. Please note that during the production process errors may be discovered which could affect the content, and all legal disclaimers that apply to the journal pertain.
} 


\section{Wnt Co-Receptors}

While each of these pathways involves the activation of Fz receptors, co-receptors that confer specificity to the different signaling cascades are emerging as critical components of Wnt signaling (Figure 1). For instance, the mammalian lipoprotein receptor related proteins LRP5 and LRP6 and their Drosophila homologue arrow were shown to be necessary co-receptors for the canonical Wnt signaling pathway (Pinson et al., 2000); (Tamai et al., 2000) (Wehrli et al., 2000); (He et al., 2004). LRP6 forms complexes with Frizzled proteins in a Wnt dependent manner and converges intracellularly to regulate $\beta$-catenin signaling (Tamai et al., 2000).

Recently another set of receptor proteins have been implicated in Wnt signaling, particularly in axon guidance in the developing nervous system (Bovolenta et al., 2006). These proteins Ror1, Ror2 and Ryk are receptor tyrosine kinases that also bind Wnt ligands (Liu et al., 2005; Schmitt et al., 2006; Yoshikawa et al., 2003). Recent evidence suggests that the activity of these receptors may antagonize the transcriptional effects of the $\beta$-catenin dependent pathway (Baksh et al., 2007; Li et al., 2008; Medina et al., 2000; Rossol-Allison et al., 2009). Thus an interesting new model is emerging where Wnt signaling specificity is dependent upon receptor context. Indeed, one study has shown that the same ligand, Wnt5a, can be driven to induce either canonical signaling or non- canonical signaling depending on the presence of Ror or Ryk (Mikels and Nusse, 2006). With 19 known Wnt ligands, 10 Fz receptors and at least 5 known co-receptors, there is tremendous potential for a dynamic, specific and tightly regulated Wnt signaling network.

\section{Wnts in Early Development and Patterning}

Early in vertebrate development Wnt signaling controls anterior-posterior axis formation and neural patterning (Takahashi and Liu, 2006). Members of the Wnt5a class of proteins, for example, are required for proper convergent extension movements during gastrulation in zebrafish and xenopus (Moon et al., 1993; Ungar et al., 1995). In this process, polarized mesodermal cells intercalate (converge) along the anterior-posterior axis and then extend along and lengthen the neuraxis.

Later in development, anterior inhibition of canonical Wnt signaling is required for forebrain induction. Essential to this process is the establishment of a rostral-caudal Wnt gradient, as the effects of Wnts are highly dose-dependent. Both positive and negative factors are involved in creating the Wnt signaling gradient. Zebrafish headless ( $h d l$ ) mutants lack eyes, forebrain and some midbrain due to a null mutation in Tcf3, a transcription factor that represses Wnt target genes in anterior domains (Kim et al., 2000). Likewise, ectopic expression of some Wnts in posterior regions mimics the $h d l$ phenotype. For example, overexpression of Wnt8c in a transgenic mouse model results in the complete loss of anterior forebrain, midbrain and other anterior neural structures (Popperl et al., 1997). Thus in some vertebrates low levels of anterior Wnt activity and high posterior levels are required for proper patterning of neural structures along the A-P axis.

It is less clear if Wnt inhibition is essential for mammalian forebrain development, but evidence from the LRP6 mutant mouse indicates a similar gradient may be operative in at least some subregions of the forebrain (Zhou et al., 2004a). In the cortex, the most prominent loss-offunction phenotypes were first noted in the hippocampus and dentate gyrus, which develop immediately adjacent to the Wnt rich signaling center called the cortical hem (Grove et al., 1998).

In addition to Wnts, fibroblast growth factors (FGFs) FGF8 and FGF17 are important for A$\mathrm{P}$ patterning. FGF8, for example, is expressed in the midbrain primordium and is responsible for midbrain patterning along the anterior-posterior axis (Crossley et al., 1996; Shamim et al., 
1999). Overexpression of FGF8 in the anterior cortical primordium increases the size of anterior structures and shrinks posterior regions of the brain. In contrast, suppression of FGFs in anterior regions enhances posterior structures at the expense of anterior structures (FukuchiShimogori and Grove, 2001).

\section{Wnt3a and the cortical hem}

The cortical hem is located at the edge of the dorsomedial cortical primordium and establishes medial-lateral patterning of the dorsal telencephalon, including the hippocampus. The cortical hem is a source of both Wnt and BMP proteins (Furuta et al., 1997; Grove et al., 1998; Lee et al., 2000). Wnt3a mutant mice are missing virtually the entire hippocampus and have a transition from laminated neocortex to fimbria with a severe foreshortening of the medial cortical wall that usually comprises the hippocampal formation (Lee et al., 2000). Molecular analysis of these mutants using markers for cell proliferation shows that they have a dramatic decrease in cell division within the hippocampal neuroepithelium. However there remain small reservoirs of cells expressing cell type specific markers of dentate gyrus, CA3 and CA1 hippocampal subfields. This implies that Wnt3a primarily regulates proliferation of hippocampal neural precursor cells, but not cell type specification.

Lef1 and LRP6 mutant mice have a much more selective hippocampal defect in the dentate neuroepithelium and fail to produce dentate granule neurons (Galceran et al., 2000; Zhou et al., 2004b). Canonical Wnt signaling has also been shown to be important in regulating proliferation of neural precursors in the adult dentate gyrus, suggesting that this function may be the adult equivalent of the embryonic failure in proliferation of dentate precursors (Lie et al., 2005).

\section{Wnts in the developing neocortical ventricular zone}

Evidence is also accumulating that Wnt signaling plays an important role in the regulation of proliferation, cell cycle exit and neurogenesis in the developing neocortical ventricular zone (VZ). Overexpression of dominant active $\beta$-catenin in the VZ using the nestin promoter yielded mice with derangements in overall proliferative control of cortical neural precursors (Chenn and Walsh, 2002). It is important to remember, however, that overexpression may not indicate normal function in these processes. Follow up studies examining mice with selective loss of function of $\beta$-catenin in the neocortical VZ may also indicate a role for Wnts in cortical development (Woodhead et al., 2006), but it is unclear if this effect is specific to Wnt signaling or instead reflects the non Wnt-related role of $\beta$-catenin in the adherens complex (Willert and Jones, 2006).

Data combining analysis of Wnt reporter plasmids and mosaic loss-of-function for $\beta$-catenin adds to our understanding of the role of Wnts in the VZ. These studies indicate that Wnt signaling is strong in the VZ (Noles and Chenn, 2007) and is immediately down-regulated upon the exit of cells to the subventricular zone and intermediate zone (Bonnert et al., 2006). Interestingly, small numbers of neurons reaching the cortical plate reinitiate strong canonical Wnt signaling in neuronal development. LRP6 mutant mice exhibit neocortical defects that are consistent with an essential role for canonical Wnt signaling in the neocortical VZ (Zhou et al., 2004b).

\section{Wnts and Axon Growth, Guidance, and Remodeling}

Wnts are involved in other aspects of axon guidance and remodeling. In both the cerebellum and spinal cord, the presence of Wnt7a and Wnt3 (respectively) result in increased growth cone size and complexity, increased axon diameter, and the induction of axon branching (Ciani and Salinas, 2005; Hall et al., 2000). Dorsal root ganglion explants grown in Wnt3a conditioned 
media display longer, more numerous neurites as compared with those grown in control media (Lu et al., 2004).

The molecular mechanisms for these Wnt effects are still being elucidated. Wnt3a-induced neurite outgrowth is reduced by the addition of Ryk siRNA, suggesting Ryk is a required coreceptor for this particular Wnt function (Lu et al., 2004). While the canonical pathway is not directly involved in axon guidance, it is possible that the stabilization of $\beta$-catenin may play a role by indirectly affecting cadherin-mediated adhesion (Zou, 2004). Furthermore, Wnts and Disheveled (DVL) influence microtubule stability, hence changing the dynamics of the cytoskeleton. As this occurs via the canonical pathway through inhibition of GSK3 $\beta$, it indicates a potential role for the canonical pathway in axon remodeling (Ciani and Salinas, 2005).

Wnts also play an essential role in guiding commissural axons in the spinal cord. The Wnt4Fz3 interaction regulates anterior-directed projections once they have crossed the midline, and Wnt4 stimulates the turning of these commissural neurons (Lyuksyutova et al., 2003). The commissural axons of Fz3 mutants project randomly once they have crossed the midline and also exhibit defects in thalamocortical, cortiothalamic, and nigrostriatal axon tracts (Bovolenta et al., 2006). Likewise, the Wnt5-Ryk interaction is important in the establishment of major brain tracts like the corpus callosum and cortico-spinal tract. In Ryk null mice, axons cannot exit the corpus callosum once they reach the contralateral side (Keeble and Cooper, 2006; Keeble et al., 2006). Wnt5a is the demonstrated ligand for Ryk in this role.

Wnts can function as both chemoattractive and chemorepulsive cues in axon guidance, depending on the receptor. Fzs seem to mediate a chemoattractive role for Wnts while Ryk and Derailed (ABB) confer repulsive behaviors (Bovolenta et al., 2006; Ciani and Salinas, 2005; Zou, 2004). For example, Wnt1 and Wnt5a are attractive to commissural neurons with Fz receptors while these same Wnts are repulsive to cortico-spinal and callosal axons with Ryk receptors (Bovolenta et al., 2006; Liu et al., 2005; Lyuksyutova et al., 2003).

\section{Wnts and Synapse Formation}

Because of the strong role Wnts play in axon guidance, it has been hypothesized that they may also influence synapse formation. Indeed, many Wnt ligands and other Wnt-related factors that affect axon growth and remodeling are also involved in forming synapses along axons. Wnt7a for example is expressed by granule cells during postnatal days 12-22, a time of synapse formation in the mouse cerebellum. The presence of Wnt7a increases synapsin I clustering and causes growth cone enlargement, both of which are key to synapse formation (Hall et al., 2000). Conversely, Wnt7a null mice have a delay in synapsin I clustering and less complicated mossy fiber axonal rosettes (Hall et al., 2000). Dvl appears to play a role as well, since Wnt7a/ Dvl1double null mutants have an even further reduction in rosette convolutions (AhmadAnnuar et al., 2006). These mice also display a decrease in the frequency of miniature excitatory postsynaptic currents (Ahmad-Annuar et al., 2006; Chen et al., 2006), a functional demonstration of the anatomical defects.

Wnt3 also appears to influence synapse development. As with Wnt7a, Wnt3 is expressed in motor neurons as they form synapses with sensory neurons. The addition of Wnt 3 to sensory neuron cultures resulted in synapsin-I clustering and growth cone enlargement (Krylova et al., 2002). Wnt3a adjusts the progression patterns of growth cones, making them more conducive to synapse formation (Purro et al., 2008). For example, in cultured dorsal root ganglion neurons, Wnt3a decreases the speed of growth cone advancement while increasing their size (Purro et al., 2008). It also increases the proportion of growth cones with looped (vs. splayed) microtubules, which is associated with paused growth cones that may be forming synapses. This effect appears to be dependent on the canonical pathway, as transfecting cultured DRG 
cells with Dvl mimicked these results while a constitutively active form of Gsk3 $\beta$ blocked them (Purro et al., 2008).

There is evidence of a role for Wnts in synaptic transmission and plasticity as well. Wnt3a is rapidly released upon tetanic stimulation in mouse hippocampal slice culture, which induces the accumulation of $\beta$-catenin in the nucleus and up-regulates several Wnt target genes. Moreover, the application of anti-Wnt3a reduces the magnitude of the resulting long-term potentiation (Chen et al., 2006). A potential role for Wnt agonists was also recently shown in adult rat hippocampus by Beaumont et al. (2007). Additionally, Wnt7a is implicated in enhancing synaptic transmission presynaptically by increasing neurotransmitter release in rat hippocampus (Cerpa et al., 2008). Thus it appears likely that canonical Wnt signaling modulates both synaptic transmission and long-term potentiation.

\section{Wnts and Dendrite Development}

The complexity of dendritic arbors is directly affected by Wnts. When hippocampal cultures are treated with Wnt $7 \mathrm{~b}$ conditioned media, the neurons exhibit longer dendrites with an increased number of branches. Conversely, the addition of a Wnt inhibitor, sFRP, to these cultures decreases arbor complexity. Moreover, hippocampal cultures taken from Dvl1 deficient mice display a simpler dendritic arbor (Rosso et al., 2005). A similar increase in dendritic branches and length is observed in hippocampal cultures in the presence of Wnt2a conditioned media or when transfected with a Wnt2 expressing construct (Wayman et al., 2006). This enhancement is blocked by Wif, an inhibitor that prevents Wnt from activating its Frizzled receptor, further demonstrating the requirement for Wnt in dendritic outgrowth. Hence it appears that Wnt signaling regulates dendritic development.

Yu and Malenka (2003) found that $\beta$-catenin also influences dendritic complexity of hippocampal neurons in vitro. Cells transfected with a stabilized form of GFP- $\beta$-catenin had an increase in the number of dendritic branches that was proportional to the amount of $\beta$-catenin expressed. In contrast, sequestering $\beta$-catenin by overexpressing $\mathrm{N}$-cadherin significantly decreased dendritic arborization.

Wnt effects on dendrite development are also activity dependent. In a study by Wayman et al. (2006), neuronal activity triggers a calcium signaling pathway that leads to the transcription of Wnt2. Moreover, activity-dependent dendrite growth is blocked by Wnt antagonists, revealing a potential mechanism by which neuronal activity may mediate neurite outgrowth; similar results were obtained by Yu and Malenka (2003). They determined that high K+ concentrations in hippocampal cultures (which mimics neuronal depolarization) increased the number of dendritic branches, an effect that was enhanced with stabilized $\beta$-catenin. However, sequestering $\beta$-catenin or adding a Wnt antagonist reversed the effects of neuronal activity. Hence Wnts are able to exert effects over dendritic outgrowth and complexity under different circumstances.

\section{Wnts and non-neuronal cells in the CNS}

Wnts also play a role in the development and function of glial cells of the CNS. The Wnt pathway regulates oligodendrocyte differentiation and subsequent myelination. Mutants expressing a floxed stabilized form of $\beta$-catenin were crossed with Olig 1 -cre to produce constituitive Wnt signaling in oligodendrocytes. Oligodendrocyte differentiation was inhibited in the spinal cords of these animals, suggesting that Wnt signaling regulates oligodendrocyte development (Ye et al., 2009). In addition, $T c f 7 l 2$, a transcription factor that participates in Wnt signaling, plays a role in oligodendrocyte differentiation and maturation (Ye et al., 2009). In experiments using BAT-gal reporter mice, canonical Wnt signaling is regulated during oligodendrocyte development and during periods of remyelination following 
demyelination (Fancy et al., 2009). Over-activation of the Wnt pathway inhibits both normal developmental myelination as well as remyelination after injury (Fancy et al., 2009). Thus the Wnt signaling pathway plays a key role in the development of oligodendrocytes and the myelin that they produce.

Wnts have also been implicated in angiogenesis of the central nervous system. When $\beta$-catenin is selectively knocked-out of endothelial cells, non-neural vasculature forms normally.

However, the central nervous system shows defects including a lack of capillaries throughout the forebrain and spinal cord, a thickened perineural vascular plexus, and a thickened neuroectodermal cell layer resulting in increased ventricles (Daneman et al., 2009). Similarly, injection of adenoviruses encoding a soluble Frizzled 8-Fc fusion to act as a Wnt inhibitor results in CNS vasculature malformations. At E12.5, Wnt7a/b double knockout mice, which are embryonic lethal, demonstrate endothelial cells, pericytes and blood vessels that are abnormal in the dorsal neural tube and absent in the ventral neural tube (Stenman et al., 2008). These mice also have a thickened vascular plexus (Daneman et al., 2009). When $\beta$ catenin is removed from vascular precursors, endothelial cells and pericytes were absent from the neuroepithelium (Stenman et al., 2008), emphasizing the crucial role of Wnts in the formation of CNS vasculature.

\section{Wnts and Dentate Neurogenesis}

Wnts also play fundamental roles in regulating the proliferative behavior of progenitors in the adult dentate gyrus where they are one of the main controllers of the addition of new neurons into the hippocampal circuit (Pozniak and Pleasure, 2006). Gage and colleagues showed that a subgroup of hilar astrocytes produces Wnt 3 and that Wnt signaling is essential for maintaining the proliferation of subgranular zone progenitors (Lie et al., 2005). Many mechanistic questions remain but it is tempting to assume that Wnts regulate the maintenance of the radial glial network in the dentate gyrus in adulthood as they also have a key role in the development of this specialized germinal matrix (Zhou et al., 2004b).

\section{Wnts and Nervous System Disease}

Defects in Wnts or related proteins often result in derangements in axonal pathways, including commissural axon tracts such as the corpus callosum. The glial wedge is key to the formation of the corpus callosum. This structure is comprised of radial glial cells that prevent callosal axons from entering the septum and repels axons away from the midline once they have crossed into the contralateral hemisphere. This guidance depends on Wnt-Ryk signaling, disruptions of which cause defects in corpus callosum formation in mice (Keeble and Cooper, 2006). Furthermore, Fz3 null mutants have defects in major commissural fiber tracts including the complete absence of the corpus callosum (Wang et al., 2002).

Patients with agenesis of the corpus callosum $(\mathrm{AgCC})$ demonstrate a number of behavioral abnormalities (Paul et al., 2007). Overall their IQ scores are within the normal range, although they frequently measure lower than predicted by their family history. While they perform well on tasks with easily encoded stimuli, they have difficulties with more complex tasks and struggle with abstract reasoning, problem solving, generalization and category fluency. $\mathrm{AgCC}$ patients also exhibit impairments in language, social skills, personal insight, and emotional processing. Hence, the effects of Wnt defects can manifest as significant behavioral issues and it is quite likely that disturbances in Wnt signaling will prove to be among the causes of this very pleiotrophic developmental malformation.

Various components of the Wnt signaling pathway have been implicated in neural tube defects (NTD). $D v l 2$ null mutants have thoracic spina bifida and $D v l 1 / 2$ double mutants produce even more severe NTD (Hamblet et al., 2002). Mutations of axin, a Wnt pathway inhibitor, can result 
in incomplete closure of the neural tube or malformation of the head folds (Zeng et al., 1997). Alterations (hypoactivity, hyperactivity and missense mutations) to LRP6, a Wnt coreceptor required for signaling via the frizzled pathway, can also cause NTD (Carter et al., 2005; Kokubu et al., 2004; Pinson et al., 2000). Recently it has been demonstrated that a mutation of LRP6 causes the crooked tail mutation in mice that exhibit NTD, which can be ameliorated by dietary folic acid (Carter et al., 2005). The benefits of folic acid in closing the neural tube have also been demonstrated in human development, so understanding the role of the Wnt pathway in neurulation has important clinical implications.

A subset of primitive neuroectodermal tumors (PNETS) result from tonic Wnt pathway activation. Mutations that lead to nuclear accumulation of $\beta$-catenin are present in some cerebellar and cerebral PNETS (Koch et al., 2001; Zurawel et al., 1998). While stabilized $\beta$ catenin is not sufficient to cause brain tumor development (Kratz et al., 2002), stabilized $\beta$ catenin together with forced expression of c-Myc, a downstream target of the Wnt signaling pathway, does result in increased tumors (Momota et al., 2008). It is possible that alteration of the Wnt pathway results in enhanced transcription of growth-related genes and proliferation, leading to tumor progression.

Wnts have also been implicated in Williams Syndrome, which is caused by a heterozygous microdeletion of approximately 20 genes on chromosome 7 (Bellugi et al., 1999). Fz9, a Wnt receptor gene, is within the chromosomal deletion interval in many patients with the typical neurodevelopmental phenotype. This neurodevelopmental disorder is characterized by a friendly, effusive personality, enhanced language ability, preserved social function, a high incidence of seizures, and impaired spatial cognition (Doyle et al., 2004). Mice with null mutations in Fz9 have neurodevelopmental defects in the dentate gyrus, visuospatial memory defects and lowered seizure threshold (Zhao et al., 2005). Since mice with one inactivated allele (sharing the same genotype as Williams patients for this gene) have an intermediate form of this dysfunction (Zhao et al., 2005), it seems likely that loss of Fz9 is responsible for some of the cognitive findings seen in Williams patients. Williams patients have neuroanatomical abnormalities including decreased volume of the occipital cortex and increased volume of the superior temporal region (Schmitt et al., 2001). Since Wnts influence both programmed cell death and cell proliferation, the loss of a Fz9 gene may play a role in these cortical volume defects.

\section{Conclusions}

The Wnt signaling pathway is one of the most protean in vertebrate development. It is involved in patterning and proliferation of many of the cell lineages in embryos and this extends to the central nervous system as well. In addition, in recent years as the roles of Wnt signaling in regulating cytoskeletal dynamics and reorganization have become apparent, the canonical and non-canonical signaling pathways have been shown to play multiple and complex roles in the formation of the nervous system at every level from axon guidance to synaptic plasticity. It is also apparent that our appreciation of the role of Wnt signaling in human nervous system disease is in it's early stages still as new genetic syndromes are identified and mouse models resembling human phenoypes are characterized the importance of this pathway will be even further emphasized.

\section{References}

Ahmad-Annuar A, et al. Signaling across the synapse: a role for Wnt and Dishevelled in presynaptic assembly and neurotransmitter release. J Cell Biol 2006;174:127-39. [PubMed: 16818724] 
Baksh D, et al. Cross-talk between Wnt signaling pathways in human mesenchymal stem cells leads to functional antagonism during osteogenic differentiation. J Cell Biochem 2007;101:1109-24. [PubMed: 17546602]

Beaumont $\mathrm{V}$, et al. Evidence for an enhancement of excitatory transmission in adult CNS by Wnt signaling pathway modulation. Mol Cell Neurosci 2007;35:513-24. [PubMed: 17588772]

Bellugi U, et al. Bridging cognition, the brain and molecular genetics: evidence from Williams syndrome. Trends Neurosci 1999;22:197-207. [PubMed: 10322491]

Bonnert TP, et al. Molecular characterization of adult mouse subventricular zone progenitor cells during the onset of differentiation. Eur J Neurosci 2006;24:661-75. [PubMed: 16930398]

Bovolenta P, et al. Frizzled/RYK mediated signalling in axon guidance. Development 2006;133:4399_ 408. [PubMed: 17035295]

Carter M, et al. Crooked tail (Cd) model of human folate-responsive neural tube defects is mutated in Wnt coreceptor lipoprotein receptor-related protein 6. Proc Natl Acad Sci U S A 2005;102:12843-8. [PubMed: 16126904]

Cerpa W, et al. Wnt-7a modulates the synaptic vesicle cycle and synaptic transmission in hippocampal neurons. J Biol Chem 2008;283:5918-27. [PubMed: 18096705]

Chen J, et al. Activity-dependent synaptic Wnt release regulates hippocampal long term potentiation. J Biol Chem 2006;281:11910-6. [PubMed: 16501258]

Chenn A, Walsh CA. Regulation of cerebral cortical size by control of cell cycle exit in neural precursors. Science 2002;297:365-9. [PubMed: 12130776]

Chien AJ, et al. A Wnt survival guide: from flies to human disease. J Invest Dermatol 2009;129:161427. [PubMed: 19177135]

Ciani L, Salinas PC. WNTs in the vertebrate nervous system: from patterning to neuronal connectivity. Nat Rev Neurosci 2005;6:351-62. [PubMed: 15832199]

Crossley PH, et al. Midbrain development induced by FGF8 in the chick embryo. Nature 1996;380:668. [PubMed: 8598907]

Daneman R, et al. Wnt/beta-catenin signaling is required for CNS, but not non-CNS, angiogenesis. Proc Natl Acad Sci U S A 2009;106:641-6. [PubMed: 19129494]

Doyle TF, et al. "Everybody in the world is my friend" hypersociability in young children with Williams syndrome. Am J Med Genet A 2004;124A:263-73. [PubMed: 14708099]

Fancy SP, et al. Dysregulation of the Wnt pathway inhibits timely myelination and remyelination in the mammalian CNS. Genes Dev 2009;23:1571-85. [PubMed: 19515974]

Fukuchi-Shimogori T, Grove EA. Neocortex patterning by the secreted signaling molecule FGF8. Science 2001;294:1071-4. [PubMed: 11567107]

Furuta Y, et al. Bone morphogenetic proteins (BMPs) as regulators of dorsal forebrain development. Development 1997;124:2203-12. [PubMed: 9187146]

Galceran J, et al. Hippocampus development and generation of dentate gyrus granule cells is regulated by LEF1. Development 2000;127:469-82. [PubMed: 10631168]

Grove EA, et al. The hem of the embryonic cerebral cortex is defined by the expression of multiple Wnt genes and is compromised in Gli3-deficient mice. Development 1998;125:2315-25. [PubMed: 9584130]

Hall AC, et al. Axonal remodeling and synaptic differentiation in the cerebellum is regulated by WNT-7a signaling. Cell 2000;100:525-35. [PubMed: 10721990]

Hamblet NS, et al. Dishevelled 2 is essential for cardiac outflow tract development, somite segmentation and neural tube closure. Development 2002;129:5827-38. [PubMed: 12421720]

$\mathrm{He} \mathrm{X}$, et al. LDL receptor-related proteins 5 and 6 in Wnt/beta-catenin signaling: arrows point the way. Development 2004;131:1663-77. [PubMed: 15084453]

Huang H, He X. Wnt/beta-catenin signaling: new (and old) players and new insights. Curr Opin Cell Biol 2008;20:119-25. [PubMed: 18339531]

Keeble TR, Cooper HM. Ryk: a novel Wnt receptor regulating axon pathfinding. Int J Biochem Cell Biol 2006;38:2011-7. [PubMed: 16971168]

Keeble TR, et al. The Wnt receptor Ryk is required for Wnt5a-mediated axon guidance on the contralateral side of the corpus callosum. J Neurosci 2006;26:5840-8. [PubMed: 16723543] 
Kim $\mathrm{CH}$, et al. Repressor activity of Headless/Tcf3 is essential for vertebrate head formation. Nature 2000;407:913-6. [PubMed: 11057671]

Koch A, et al. Somatic mutations of WNT/wingless signaling pathway components in primitive neuroectodermal tumors. Int J Cancer 2001;93:445-9. [PubMed: 11433413]

Kohn AD, Moon RT. Wnt and calcium signaling: beta-catenin-independent pathways. Cell Calcium 2005;38:439-46. [PubMed: 16099039]

Kokubu C, et al. Skeletal defects in ringelschwanz mutant mice reveal that Lrp6 is required for proper somitogenesis and osteogenesis. Development 2004;131:5469-80. [PubMed: 15469977]

Kratz JE, et al. Expression of stabilized beta-catenin in differentiated neurons of transgenic mice does not result in tumor formation. BMC Cancer 2002;2:33. [PubMed: 12460454]

Krylova O, et al. WNT-3, expressed by motoneurons, regulates terminal arborization of neurotrophin-3responsive spinal sensory neurons. Neuron 2002;35:1043-56. [PubMed: 12354395]

Kuhl M, et al. Antagonistic regulation of convergent extension movements in Xenopus by Wnt/betacatenin and Wnt/Ca2+ signaling. Mech Dev 2001;106:61-76. [PubMed: 11472835]

Kuhl M, et al. $\mathrm{Ca}(2+) /$ calmodulin-dependent protein kinase II is stimulated by Wnt and Frizzled homologs and promotes ventral cell fates in Xenopus. J Biol Chem 2000a;275:12701-11. [PubMed: 10777564]

Kuhl M, et al. The Wnt/Ca2+ pathway: a new vertebrate Wnt signaling pathway takes shape. Trends Genet 2000b;16:279-83. [PubMed: 10858654]

Lee SM, et al. A local Wnt-3a signal is required for development of the mammalian hippocampus. Development 2000;127:457-67. [PubMed: 10631167]

Li C, et al. Ror2 modulates the canonical Wnt signaling in lung epithelial cells through cooperation with Fzd2. BMC Mol Biol 2008;9:11. [PubMed: 18215320]

Lie DC, et al. Wnt signalling regulates adult hippocampal neurogenesis. Nature 2005;437:1370-5. [PubMed: 16251967]

Liu Y, et al. Ryk-mediated Wnt repulsion regulates posterior-directed growth of corticospinal tract. Nat Neurosci 2005;8:1151-9. [PubMed: 16116452]

$\mathrm{Lu}$ W, et al. Mammalian Ryk is a Wnt coreceptor required for stimulation of neurite outgrowth. Cell 2004;119:97-108. [PubMed: 15454084]

Lyuksyutova AI, et al. Anterior-posterior guidance of commissural axons by Wnt-frizzled signaling. Science 2003;302:1984-8. [PubMed: 14671310]

Medina A, et al. Xenopus frizzled 7 can act in canonical and non-canonical Wnt signaling pathways: implications on early patterning and morphogenesis. Mech Dev 2000;92:227-37. [PubMed: 10727861]

Mikels AJ, Nusse R. Purified Wnt5a protein activates or inhibits beta-catenin-TCF signaling depending on receptor context. PLoS Biol 2006;4:e115. [PubMed: 16602827]

Momota $\mathrm{H}$, et al. c-Myc and beta-catenin cooperate with loss of p53 to generate multiple members of the primitive neuroectodermal tumor family in mice. Oncogene 2008;27:4392-401. [PubMed: 18372915]

Moon RT, et al. Xwnt-5A: a maternal Wnt that affects morphogenetic movements after overexpression in embryos of Xenopus laevis. Development 1993;119:97-111. [PubMed: 8275867]

Noles SR, Chenn A. Cadherin inhibition of beta-catenin signaling regulates the proliferation and differentiation of neural precursor cells. Mol Cell Neurosci 2007;35:549-58. [PubMed: 17553695]

Paul LK, et al. Agenesis of the corpus callosum: genetic, developmental and functional aspects of connectivity. Nat Rev Neurosci 2007;8:287-99. [PubMed: 17375041]

Pinson KI, et al. An LDL-receptor-related protein mediates Wnt signalling in mice. Nature 2000;407:5358. [PubMed: 11029008]

Popperl H, et al. Misexpression of Cwnt8C in the mouse induces an ectopic embryonic axis and causes a truncation of the anterior neuroectoderm. Development 1997;124:2997-3005. [PubMed: 9247341]

Pozniak CD, Pleasure SJ. A tale of two signals: Wnt and Hedgehog in dentate neurogenesis. Sci STKE 2006;2006:pe5. [PubMed: 16434726]

Purro SA, et al. Wnt regulates axon behavior through changes in microtubule growth directionality: a new role for adenomatous polyposis coli. J Neurosci 2008;28:8644-54. [PubMed: 18716223] 
Rosso SB, et al. Wnt signaling through Dishevelled, Rac and JNK regulates dendritic development. Nat Neurosci 2005;8:34-42. [PubMed: 15608632]

Rossol-Allison J, et al. Rho Gtpase activity modulates Wnt3a/beta-Catenin Signaling. Cell Signal. 2009

Schmitt AM, et al. Wnt-Ryk signalling mediates medial-lateral retinotectal topographic mapping. Nature 2006;439:31-7. [PubMed: 16280981]

Schmitt JE, et al. Analysis of cerebral shape in Williams syndrome. Arch Neurol 2001;58:283-7. [PubMed: 11176967]

Semenov MV, et al. SnapShot: Noncanonical Wnt Signaling Pathways. Cell 2007;131:1378. [PubMed: 18160045]

Shamim H, et al. Sequential roles for Fgf4, En1 and Fgf8 in specification and regionalisation of the midbrain. Development 1999;126:945-59. [PubMed: 9927596]

Slusarski DC, et al. Modulation of embryonic intracellular Ca2+ signaling by Wnt-5A. Dev Biol 1997;182:114-20. [PubMed: 9073455]

Stenman JM, et al. Canonical Wnt signaling regulates organ-specific assembly and differentiation of CNS vasculature. Science 2008;322:1247-50. [PubMed: 19023080]

Takahashi H, Liu FC. Genetic patterning of the mammalian telencephalon by morphogenetic molecules and transcription factors. Birth Defects Res C Embryo Today 2006;78:256-66. [PubMed: 17061260]

Tamai K, et al. LDL-receptor-related proteins in Wnt signal transduction. Nature 2000;407:530-5. [PubMed: 11029007]

Ungar AR, et al. Wnt4 affects morphogenesis when misexpressed in the zebrafish embryo. Mech Dev 1995;52:153-64. [PubMed: 8541205]

Wang Y, et al. Frizzled-3 is required for the development of major fiber tracts in the rostral CNS. J Neurosci 2002;22:8563-73. [PubMed: 12351730]

Wang Y, et al. Axonal growth and guidance defects in Frizzled3 knock-out mice: a comparison of diffusion tensor magnetic resonance imaging, neurofilament staining, and genetically directed cell labeling. J Neurosci 2006;26:355-64. [PubMed: 16407530]

Wayman GA, et al. Activity-dependent dendritic arborization mediated by CaM-kinase I activation and enhanced CREB-dependent transcription of Wnt-2. Neuron 2006;50:897-909. [PubMed: 16772171]

Wehrli M, et al. arrow encodes an LDL-receptor-related protein essential for Wingless signalling. Nature 2000;407:527-30. [PubMed: 11029006]

Willert K, Jones KA. Wnt signaling: is the party in the nucleus? Genes Dev 2006;20:1394-404. [PubMed: 16751178]

Woodhead GJ, et al. Cell-autonomous beta-catenin signaling regulates cortical precursor proliferation. J Neurosci 2006;26:12620-30. [PubMed: 17135424]

Ye F, et al. HDAC1 and HDAC2 regulate oligodendrocyte differentiation by disrupting the beta-cateninTCF interaction. Nat Neurosci 2009;12:829-38. [PubMed: 19503085]

Yoshikawa S, et al. Wnt-mediated axon guidance via the Drosophila Derailed receptor. Nature 2003;422:583-8. [PubMed: 12660735]

Yu X, Malenka RC. Beta-catenin is critical for dendritic morphogenesis. Nat Neurosci 2003;6:1169-77. [PubMed: 14528308]

Zeng L, et al. The mouse Fused locus encodes Axin, an inhibitor of the Wnt signaling pathway that regulates embryonic axis formation. Cell 1997;90:181-92. [PubMed: 9230313]

Zhao C, et al. Hippocampal and visuospatial learning defects in mice with a deletion of frizzled 9, a gene in the Williams syndrome deletion interval. Development 2005;132:2917-27. [PubMed: 15930120]

Zhou CJ, et al. Severe defects in dorsal thalamic development in low-density lipoprotein receptor-related protein-6 mutants. J Neurosci 2004a;24:7632-9. [PubMed: 15342729]

Zhou CJ, et al. Wnt signaling mutants have decreased dentate granule cell production and radial glial scaffolding abnormalities. J Neurosci 2004b;24:121-6. [PubMed: 14715945]

Zou Y. Wnt signaling in axon guidance. Trends Neurosci 2004;27:528-32. [PubMed: 15331234]

Zurawel RH, et al. Sporadic medulloblastomas contain oncogenic beta-catenin mutations. Cancer Res 1998;58:896-9. [PubMed: 9500446] 


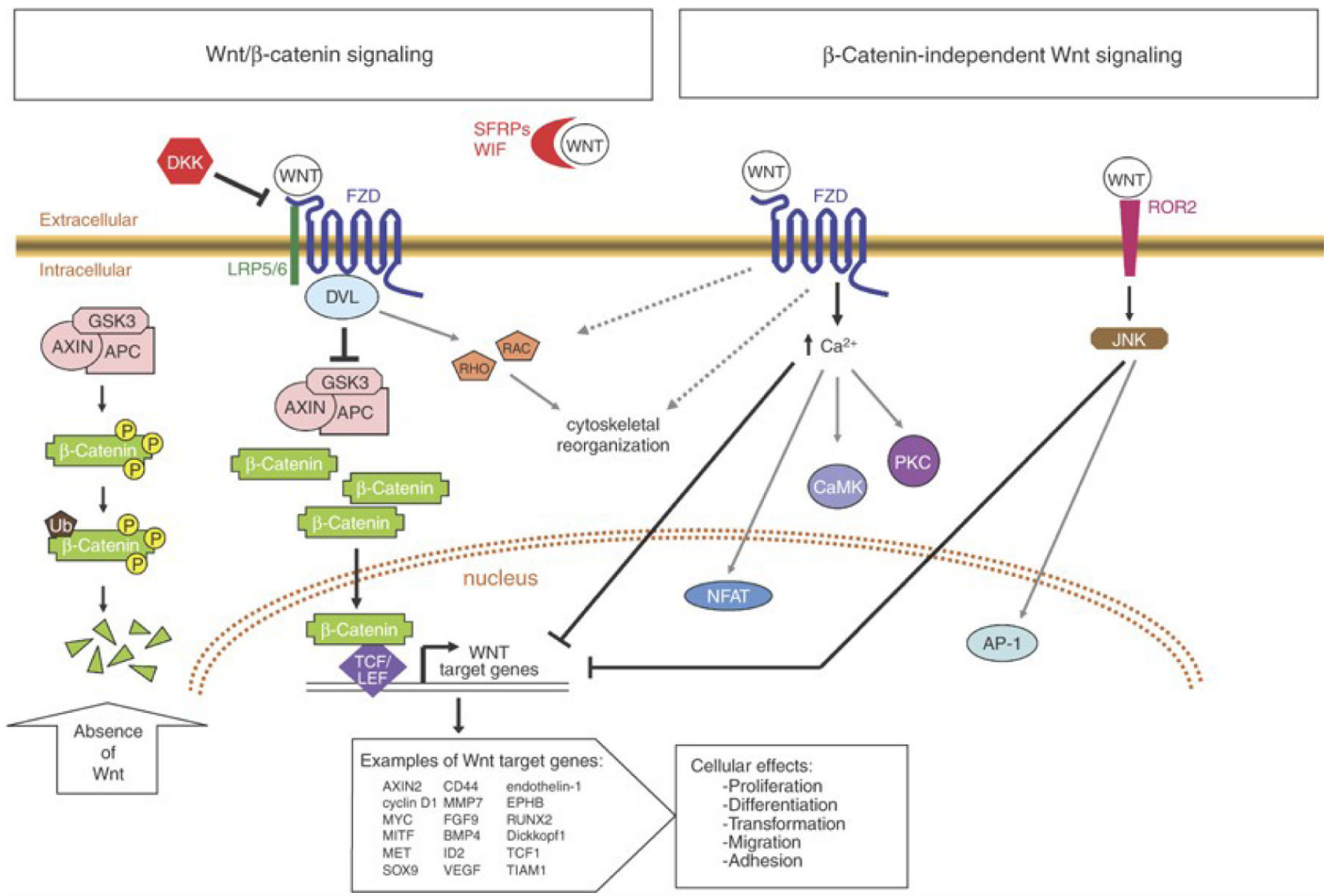

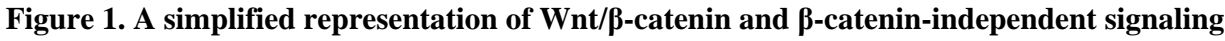
pathways

In the absence of Wnt ligand (far left), the "destruction complex" composed of the core proteins Axin, adenomatous polyposis coli (APC), and glycogen synthase kinase-3 (GSK3) rapidly phosphorylates $(\mathrm{P})$ cytosolic $\beta$-catenin, targeting it for subsequent ubiquitination $(\mathrm{Ub})$ and proteasome-mediated destruction. Binding of Wnt to Frizzled (Fzd) and low-density lipoprotein receptor-related protein 5/6 (LRP5/6) activates the cytosolic protein Dishevelled (DVL), leading to inhibition of the destruction complex. The resulting accumulated $\beta$-catenin can then translocate to the nucleus to activate Wnt-responsive target genes regulated by TCF and LEF family transcription factors, leading to various cellular effects. Activation of the small GTPases Rho and Rac can result in cytoskeletal rearrangements that affect cellular motility upon Wnt stimulation. Binding of Wnt isoforms to either Fzd or receptors such as receptor tyrosine kinase-like orphan receptor 2 (Ror2, a receptor for Wnt-5a), can trigger $\beta$-cateninindependent downstream signaling events, including the inhibition of Wnt/-catenin signaling. The mechanisms underlying $\beta$-catenin-independent Wnt signaling are not well defined, and may be largely determined by cellular context. The secreted inhibitor Dickkopf (DKK) can antagonize Wnt signaling by competitively binding to LRP5/6. Secreted Fzd-related proteins (SFRPs) and Wnt inhibitory factor (WIF) are thought to antagonize Wnt signaling by sequestering Wnt ligand in the extracellular space. (Figure originally published in (Chien et al., 2009). 